Approches des domaines spécialisés en anglais de spécialité

\title{
Harvey, Malcolm, Catherine Kirby-Légier et Marion Charret-Del Bove. Droit anglais et droit américain : cours et exercices corrigés
}

Paris : Armand Colin, 2011

\section{Marc Deneire}

\section{(2) OpenEdition}

\section{Journals}

Édition électronique

URL : http://journals.openedition.org/asp/2705

DOI : 10.4000/asp.2705

ISSN : 2108-6354

\section{Éditeur}

Groupe d'étude et de recherche en anglais de spécialité

\section{Édition imprimée}

Date de publication : 15 mars 2012

Pagination : 90-91

ISSN : 1246-8185

\section{Référence électronique}

Marc Deneire, "Harvey, Malcolm, Catherine Kirby-Légier et Marion Charret-Del Bove. Droit anglais et droit américain : cours et exercices corrigés », ASp [En ligne], 61 | 2012, mis en ligne le 15 mars 2012, consulté le 03 novembre 2020. URL : http://journals.openedition.org/asp/2705 ; DOI : https://doi.org/ 10.4000/asp.2705

Ce document a été généré automatiquement le 3 novembre 2020.

Tous droits réservés 
Harvey, Malcolm, Catherine KirbyLégier et Marion Charret-Del Bove. Droit anglais et droit américain : cours et exercices corrigés

Paris : Armand Colin, 2011

Marc Deneire

\section{RÉFÉRENCE}

Harvey Malcolm, Catherine Kirby-Légier et Marion Charret-Del Bove. 2011. Droit anglais et droit américain : cours et exercices corrigés. Paris : Armand Colin, collection Cursus, 192 p. ISBN 978-2-2002-7030-8. 
1 Cet ouvrage récent, publié dans la collection Cursus chez Armand Colin, est destiné à un public de sciences politiques, de LEA, de droit et du double cursus droitanglais. La première partie, écrite par Malcom Harvey est une introduction au droit anglais; la deuxième, rédigée par Catherine Kirby-Légier, présente le droit américain et la troisième, composée par Marion Charret-Del Bove propose une série d'exercices d'application. Dans l'avant-propos, les auteurs invitent leurs lecteurs à consulter le blog d'une des auteurs ${ }^{1}$ qui offre un répertoire structuré de sites Internet sur toutes les thématiques.

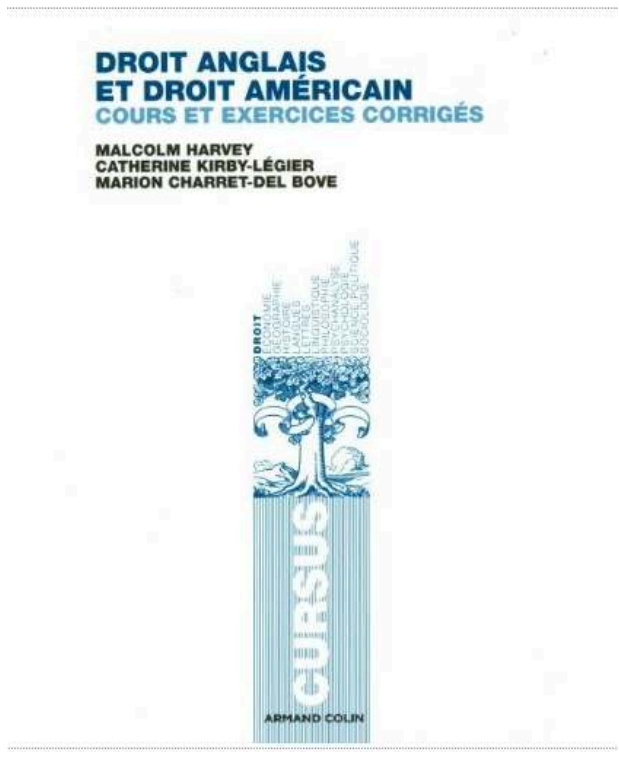

2 Étudiants et enseignants auront sans

doute à cœur, dans un deuxième temps, de consulter ces sites, tant cet ouvrage présente une introduction succincte des sujets abordés. On se trouve ici définitivement plus dans le genre du "précis» que de l'élaboration. Ce genre, retenu par les animateurs de la collection, ne manque certes pas de vertus pédagogiques. Il permet aux auteurs de répondre aux attentes des étudiants et des enseignants débutants en leur fournissant des définitions précises des concepts et des termes utilisés, avec, le cas échéant, une explication supplémentaire en note de bas de page.

3 La véritable originalité de l'ouvrage réside dans son approche comparative qui met constamment en parallèle les systèmes français, américain et britannique. Le premier chapitre de la partie américaine, intitulé «The adaptation of English law to conditions in America " montre comment le système juridique américain s'est progressivement émancipé de son parent britannique lors de la période coloniale, les deux systèmes s'adaptant à des évolutions politiques et sociales très différentes. C'est toute la structure de la pensée juridique, nous dit l'auteur, qui s'en est trouvée affectée, au point que les mêmes mots ne portent plus le même sens, d'où la nécessité d'un éclairage comparatif. Un chapitre très court en fin de deuxième partie est consacré à la comparaison entre le système français d'une part, et les systèmes américain et britannique d'autre part, mais c'est bien l'ensemble du livre qui repose sur cette comparaison. La partie britannique présente des tableaux comparatifs en fin de chapitre. De plus, la discussion sur la réforme constitutionnelle de 2005 relative à la séparation de la justice, du Parlement et de l'exécutif et les réformes subséquentes imposées par le rapprochement avec l'Union européenne montre à quel point la réforme a altéré l'institution judiciaire britannique. Dans la partie américaine, la perspective comparative semble dépasser le souci explicatif pour devenir un objectif en soi. La démarche illustre le souci des auteurs qui expliquent en conclusion que la capacité à comparer les systèmes français et anglo-saxons sera sans doute aussi utile dans la future vie professionnelle des étudiants que la maîtrise de l'anglais lui-même. À travers son exposé, l'auteure fait montre de son expérience et de ses qualités pédagogiques en approfondissant les points les plus difficiles. Dans d'autres parties, elle adopte une approche par les cas. Elle en choisit un certain nombre à titre d'exemple, 
adopte la méthode socratique sous forme de questions ouvertes et y répond brièvement dans les notes de bas de page.

Enfin la troisième partie, de longueur équivalente aux deux autres (52 pages), offre des exercices liés aux parties 1 et 2 en adoptant la même division en chapitres (sources, civil law, criminal law, etc.). On y trouve des exercices variés de compréhension, de «rebrassage » et de fixation de vocabulaire, de traduction, ainsi qu'un entraînement centré sur la forme : nominalisation, voix passive, prépositions ou même accentuation. Le premier type d'exercice permettra aux étudiants d'éclaircir certains concepts et favorisera la rétention alors que le second assurera, parallèlement, leur développement linguistique dans leur domaine de spécialité.

5 La bibliographie et la webographie en fin de chapitre comprennent une section sur les ouvrages anglais et américains portant sur le droit français, confirmant ainsi le désir de développer des regards croisés sur les systèmes juridiques. La webographie renvoie également aux cas précis mentionnés dans le corps du texte.

En conclusion, la concision et la méthode comparative adoptée ici permettent aux auteurs de répondre de façon originale, innovante et précise aux nombreuses questions que se posent les étudiants et les enseignants novices en anglais juridique, ce qui permet de prévoir à cet ouvrage un avenir prometteur aux niveaux national et international.

\section{NOTES}

1. <http://www.englishforlaw.blogspot.fr/>

\section{AUTEURS}

\section{MARC DENEIRE}

Université Nancy/IDEA EA 2338 